\title{
Espaço e planejamento urbano na sociedade contemporânea: políticas públicas e a busca por uma marca identitária na cidade de Curitiba
}

Simone Rechia

\begin{abstract}
Resumo: Diante das transformações espaciais e sociais ocorridas nas últimas décadas nas grandes metrópoles, tornam-se oportunas as discussões relativas ao planejamento urbano quando se pretende analisar o "sentido da forma" de alguns espaços das cidades. Esse é o ponto de partida para este artigo, pois o processo de formação do espaço urbano de Curitiba é percebido, inicialmente, como uma mudança morfológica, que tem como pano de fundo alguns paradigmas do processo de modernização das cidades, entre eles a busca por marcas identitárias. Pretendo, nesta breve análise, apontar algumas características das formas de produção de espaços pelas quais a prática urbanística e arquitetônica tem passado, dando uma ênfase especial às tendências contemporâneas.
\end{abstract}

Palavras-chave: cidade, planejamento urbano, políticas públicas, espaço.

\section{Introdução}

Autores contemporâneos ao analisarem as conseqüências geradas ao espaço urbano após a Segunda Guerra Mundial quando foram exigidas das práticas urbanísticas e arquitetônicas intervenções que promovessem a reconstrução das cidades modernas, questionam as práticas urbanísticas surgidas e apontam tendências que a partir deste momento passaram a ser adotadas. Uma dessas tendências se configura em modelos que buscam marcas identitárias ${ }^{1}$

1 Aqui, o termo marca identitária é utilizado no sentido dado por Yázigi (2001:49), que entende a idéia identitária de um lugar como uma "diferenciação espacial que reúna um conjunto de características fundamentada na geografia física; em suas instituições: sua vida econômica, social e cultural (com destaque para a paisagem instituicúda). construida). Trata-se de um fenômeno total, hão reduzivel a uma unica propriedade, sob o risco de perda de seu caráter [...] a identidade regional e acentuada pela natureza e a identidade local por todas as formas de construção arquitetônicourbanístico, com tudo que comportam em si".

Movimento, Porto Alegre, v. 11, n. 3, p. 49-66, setembro/dezembro de 2005 
para as cidades. Portanto, tenho a intenção de refletir como essa tendência vêm se consolidando através dos tempos.

Harvey (2000:69), ao refletir sobre as cidades, aponta que no campo da arquitetura e do projeto urbano contemporâneo, o espaço urbano está sendo considerado como algo fragmentado, de formas passadas superpostas umas às outras com uma colagem de usos correntes, muitos dos quais podem ser efêmeros. O início desse processo pode estar localizado no planejamento urbano modernista, que trabalha quase sempre com o zoneamento monofuncional, onde a circulação das pessoas por meio de artérias artificiais se torna a principal preocupação do planejador. Na esteira das formulações de Harvey, Szmrecsanyi (2001) afirma que atualmente esses fundamentos são freqüentemente considerados rígidos e doutrinários, sendo a escola moderna reducionista em seus valores ao se pautar na funcionalidade do espaço urbano como critério decisivo, em que estrutura e recorte são considerados pontos fortes do planejamento de uma cidade, deixando de compreendê-la na sua totalidade.

Para Harvey (2000:70), esse processo pode ter gerado um padrão urbano antiecológico da arquitetura e das paisagens urbanas atuais, resultado e expressão direta da monotonia funcionalista legislada pelas práticas de zoneamento funcional. Krier, citado por Harvey como um pós-modernista europeu, contrasta essa situação com a "boa cidade" (por sua natureza ecológica) em que a totalidade das funções urbanas é fornecida dentro de distâncias a pé compatíveis e agradáveis.

Para essa concepção de forma urbana, não é mais possível o crescimento por extensão, em largura e altura, mas sim por multiplicação, formando comunidades urbanas completas e finitas, constituindo, cada uma delas, um quarteirão urbano independente dentro de uma grande família de quarteirões urbanos, formando, por sua vez, cidades no interior de uma cidade. ${ }^{2}$ Krier

2 Curitiba, por exemplo, oferece nas chamadas "Ruas da Cidadania", serviços públicos do Município, do Estado e da União, além de comércio e lazer. A Rua da Cidadania é a filial da Prefeitura nos bairros, onde está a sede da administração Regional (são 8 ao total, distribuídas em diferentes regiões da cidade), que tem Regional (são 8 ao total, distribuidas em diferentes regiōes da cidade), que tem como função a coordenação da atuação dos diversos órgãos públicos junto à comunidade. De forma a atuar dentro do princípio da descentralização da administração pública e garantir o acesso da população aos serviços ofertados, as Ruas da Cidadania estão sendo implantadas junto ou próximo a terminais de transporte. As Ruas da Cidadania têm como objetivo, segundo documentos da Prefeitura Municipal de Curitiba (2001), aproximar os cidadãos das ações e dos serviços públicos para melhor conhecer e atender às suas necessidades; adequar as ações e os serviços prestados pela PMC às características de cada região do município; facilitar o acesso aos serviços e às informações em geral da PMC; favorecer o

Movimento, Porto Alegre, v. 11, n. 3, p. 49-66, setembro/dezembro de 2005 
salienta que somente nessas condições poderia se recuperar a riqueza simbólica urbana. O autor sugere a busca, a restauração e a recriação ativa dos valores urbanos clássicos tradicionais. O seu projeto, por certo, apóia-se em uma determinada concepção de modernismo como ponto de partida reativo. Referindo-se às formulações de Krier, Harvey (2000:70) salienta que seria importante considerar até que ponto e por que tal tipo de modernismo depreciado por Krier tornou-se uma característica tão dominante da organização pós-guerra.

Para Harvey (2000:71), os problemas políticos, econômicos e sociais enfrentados pelos países capitalistas avançados na esteira da Segunda Guerra Mundial eram tão amplos quanto graves. A paz e a prosperidade deveriam ser construídas em benefício de um povo que havia dado parte de sua vida em prol de um mundo melhor. Neste sentido, era preciso que as políticas do pós-guerra tratassem de questões do pleno emprego e da habitação, entre outras questões de igual relevância. A reconstrução, reformulação e renovação do tecido urbano tornaram-se ingredientes essenciais do projeto.

Nesse quadro geral, todos os tipos de soluções foram adotados. A Inglaterra restringiu a suburbanização substituindo-a pelo planejamento de novas cidades. Foram tomadas medidas para se eliminar as habitações miseráveis e construir casas, escolas, hospitais, fábricas, entre outras, por meio da adoção dos procedimentos de planejamento racional dos sistemas de construção industrializada, que os arquitetos modernistas há muito tinham proposto. Tudo isso integrado com a racionalização dos padrões espaciais e dos sistemas de circulação para promover a igualdade, o bem-estar e o crescimento econômico.

Outros países buscaram variantes da solução britânica. Nos Estados Unidos, a deterioração do centro das cidades gerou uma estratégia de renovação urbana por meio da demolição e da reconstrução de centros urbanos mais antigos. A recuperação da região metropolitana de Nova York foi efetuada por meio da construção de auto-estradas e de pontes, do planejamento de parques urbanos e da renovação urbana. A solução americana apoiava-se

exercício da cidadania na medida em que se ampliam os espaços de reivindicação  éç cultural e de esporte da comunidade local; estabelecer um pólo de integração entre administração regional e os núcleos urbanos; servir de apoio estratégico à descentralização da administração pública municipal e diminuir a pressão sobre o sistema de transporte.

Movimento, Porto Alegre, v. 11, n. 3, p. 49-66, setembro/dezembro de 2005 
especialmente na produção de massa, nos sistemas de construção industrializada e sobre como fazer emergir o espaço urbano racionalizado, ligando-o por meio de formas individualizadas de transporte, por meio de infra-estrutura fornecida pelo Estado.

Harvey (2000:72-76) destaca que seria injusto descrever essas soluções modernistas como puros fracassos. Considera que as cidades arrasadas pela guerra, sendo reconstruídas, e suas populações abrigadas dentro das condições tecnológicas da época, espelharam o esforço geral na reconstituição do tecido urbano de modo a preservar a ordem social. Não seria verdadeiro, segundo o autor, dizer que os estilos modernistas foram preponderantes por simples razões ideológicas. A uniformidade e a padronização eram necessárias naquele momento histórico. Os ditames dos custos e eficiência, associados às restrições organizacionais e tecnológicas tiveram papel tão importante quanto a preocupação ideológica com o estilo. O autor considera errado colocar a culpa dos males urbanos do desenvolvimento do pós-guerra no movimento moderno, sem considerar a política econômica que comandava a urbanização naquele período.

O autor considera interessante lembrar, nesta discussão, as formulações de Jacobs (1961), tanto por ser ela a autora de um dos primeiros, mais articulados e mais influentes tratados antimodernistas, como por ter procurado definir toda uma abordagem para a compreensão da vida urbana. Examinando a cena urbana tal como fora construída em 1945, ela analisa e questiona os projetos voltados especialmente para pessoas de baixa renda, para pessoas de renda média, para habitações de luxo, centros culturais, centros cívicos, centros comerciais, calçadões e vias expressas, buscando enfatizar que isso não é reconstrução de cidades: trata-se de devastação de cidades. ${ }^{3}$

Essa "grande influência maligna da estupidez", de que se queixa a autora veio de uma profunda incompreensão do que são

3 Fragomeni, professor da UFPR, arquiteto, urbanista e técnico do IPPUC por vários anos, declara em entrevista realizada em abril de 2002: "Em Curitiba, no começo das reformas urbanas a linha do urbanismo era muito funcional e higienista, com um excesso de zoneamentos, rua dos bancos, rua dos shoppings. Depois chegamos à constatação de que isso, primeiro, não era ambientalmente correto, pois mos à constatação de que isso, primeiro, não era ambientalmente correto, pois gerava a necessidade deslocamento, segundo, tirava um pouco da pluralidade, da multiplicidade, que é o caráter principal da vida urbana [...] então Curitiba iniciou suas transformações com princípios extremamente funcionalistas onde a ditadura dos transportes imperou, os eixos de transporte atravessaram os bairros e os compartimentos ambientais".

Movimento, Porto Alegre, v. 11, n. 3, p. 49-66, setembro/dezembro de 2005 
as cidades. Ela observa, ainda, que é nos processos sociais de interação que deve ser concentrada a abordagem dessas questões. Referindo-se aos planejadores, a autora coloca que estes se declaram inimigos da diversidade, temendo o caos e a complexidade por considerá-los desorganizados e irracionais. Considera curioso que os planejadores das cidades não reconheçam a força da autodiversificação nem sejam atraídos pelos problemas estéticos. Na superfície, segundo a autora, parece que o pós-modernismo procura justamente descobrir maneiras de exprimir essa estética da diversidade.

Dando continuidade a essa discussão, Harvey (2000:77) referese a Jencks, quando afirma que a arquitetura pós-moderna tem como raízes duas mudanças tecnológicas. Em primeiro lugar, as comunicações contemporâneas - que derrubaram as fronteiras usuais do espaço e do tempo, produziram tanto um novo internacionalismo quanto fortes diferenciações internas em cidades e sociedades baseadas no lugar, na função e no interesse social. Em segundo lugar, as novas tecnologias dissolveram a necessidade de conjugar a produção em massa com a repetição em massa, permitindo a tal produção um caráter um pouco mais flexível, o qual gera produtos quase personalizados, que exprimem uma grande variedade de estilos. Em princípio, para Harvey, Jencks em suas considerações enuncia que a arquitetura pós-moderna é antivanguardista, o que significa que não deseja impor, ao contrário da tendência passada - e presente - dos altos modernistas, dos planejadores burocráticos e dos empreendedores autoritários.

Para Harvey (2000), os projetos urbanos devem ser mais sensíveis às tradições próprias da região, às histórias locais, gerando formas arquitetônicas especializadas que podem variar de espaços íntimos ao espetáculo, da modernidade ao tradicional. Destaca que o ambiente construído constitui elemento de um complexo de experiências urbanas, vitais para se trabalhar novas sensibilidades culturais. Para ele, o modo como os espaços de uma cidade se organizam formam uma base material a partir da qual é possível pensar e realizar novas sensações e práticas sociais.

Neste sentido, Harvey (2000:83), afirma que o pós-modernismo $^{4}$ abandona a busca modernista pela funcionalidade em meio

4 É importante ressaltar que Harvey refere-se à pós-modernidade não propriamente como uma categoria filosófica, a qual legitime uma ruptura na modernidade, mas como uma categoria filosófica, a qual legitime uma ruptura na modernidade, mas muito mais como uma condição histórica. Neste sentido, o termo "pós-modernismo" é discutido como uma condição histórico-geográfica de uma certa espécie. Essa condição está relacionada às recentes transformações nas práticas estéticas e culturais.

Movimento, Porto Alegre, v. 11, n. 3, p. 49-66, setembro/dezembro de 2005 
à atual balbúrdia e afirma uma base mais ampla para o eterno numa visão construída da continuidade histórica e da memória coletiva.

Na continuidade, Harvey cita o arquiteto Aldo Rossi ${ }^{5}$ para reforçar essa idéia trazendo argumentos diferentes:

\begin{abstract}
A destruição e a demolição, a expropriação e as rápidas mudanças do uso como resultado da especulação e da obsolescência são os sinais mais reconhecidos da dinâmica urbana moderna. Mas, além de tudo isso, as imagens sugerem o destino ininterrupto do indivíduo, de sua participação freqüentemente triste e difícil no destino do coletivo. Essa visão parece estar refletida com uma qualidade de permanência em monumentos urbanos. Monumentos, signos da vontade coletiva expressa pelos princípios da arquitetura, se oferecem como elementos primários, pontos fixos da dinâmica urbana (ROSSI, apud HARVEY, 2000:84).
\end{abstract}

Rossi fundamenta sua compreensão no conceito de "genre de vie" - um modo de vida relativamente permanente que as pessoas comuns constroem para si mesmas em certas condições ecológicas, tecnológicas e sociais.

Rossi, segundo Harvey (2000:85), tem a virtude de levar a sério o problema da referência histórica, enquanto outros pós-modernistas apenas acenam para a legitimidade histórica por meio de uma extensa, e muitas vezes eclética, citação de estilos passados. A inclinação pós-moderna de acumular toda espécie de referências a estilos passados é uma de suas características mais presentes.

Hewison apud Harvey (2000:85) destaca que o impulso de preservar o passado é parte do impulso de preservar o eu, pois o passado é o fundamento da identidade coletiva e os objetos do passado são a fonte de significação como símbolos culturais. Para ele, "o impulso nostálgico é um importante agente do ajuste à crise, é o seu emoliente social, reforçando a identidade nacional quando a confiança se enfraquece ou é ameaçada".

Alguns autores contemporâneos reforçam a idéia de que todas as pessoas trazem um museu imaginário (musée imaginaire) na mente extraído da experiência e das vivências. Portanto, é inevitável que tudo se agregue, sendo desejável que seja assim. Nesta direção, os anos 60 viram surgir com força um novo conjunto de teorias e reflexões sobre a cidade. Ao lado do potente movimento social urbano que se desenvolve nesse período no campo do urba-

5 Para Arantes (1999:123), Aldo Rossi pôs em circulação um termo que a literatura especializada acabara esquecendo: o lugar é resultante, segundo ele de "uma especializada acabara esquecendo: o lugar é resultante, segundo ele, de "uma ções aí sediadas".

Movimento, Porto Alegre, v. 11, n. 3, p. 49-66, setembro/dezembro de 2005 
nismo propriamente dito, a crítica ao racionalismo, ao funcionalismo e ao zoneamento, assim como à tecnocracia da produção de planos afirmou um conjunto de novos valores sobre a cidade. Toda a crítica ao modernismo, que então se desdobra, traz com ela um contra-movimento de afirmação de novos valores.

Em termos de publicações, três delas representam os exemplares mais significativos desse processo:

a) A publicação do livro de Jane Jacobs, Morte e Vida das Grandes Cidades Americanas, em 1961, que traz à tona um ataque militante à maneira como as cidades estavam sendo planejadas e reconstruídas. Essa obra abre espaço para valores sociais e urbanísticos tais como diversidade, uso misto, concentração, pedestrianismo, além de buscar valores das chamadas "cidades tradicionais".

b) Talvez por ter se tornado o mais conhecido da escola italiana da tipologia, a publicação de Aldo Rossi, Arquitetura da Cidade, em 1966, que traz valores eminentemente ligados à historicidade do espaço construído e à constituição da memória como campo imprescindível à compreensão, à projeção e à implementação do sentido de lugar nas cidades.

c) Em 1971, a publicação de Aprendendo com Las Vegas, de Robert Venturi, Denise Scott-Brown e Steven Iznevour que, a partir de uma leitura do "vocabulário urbano" e de uma postura pop, busca inserir conteúdos comerciais, não cultos ou não eruditos na legitimação dos processos de produção das cidades e de suas formas. Esse livro complementa e amplia conceitos já anunciados em 1966 com a publicação de Complexidade e Contradição em Arquitetura, do mesmo Robert Venturi, que apregoa um caráter híbrido para a linguagem da arquitetura.

Essas três publicações, segundo Fernandes (2001:319), "sintetizam valores fundamentais que guiarão todo um movimento de busca de rearticulação da produção da cidade, na contracorrente do pensamento dominante de então". Se a elas somarmos a participação comunitária e os valores verdes enfatizados a partir da década de 70, teremos o universo principal de referência dos embates desse período no que concerne ao urbanismo: a busca de diversidade na cidade; a sua necessária historicidade; o reconhecimento da pluralidade e da complexidade dos meios de expressão urbana; o não determinismo nas intervenções sobre a cidade.

Movimento, Porto Alegre, v. 11, n. 3, p. 49-66, setembro/dezembro de 2005 
Harvey (2000) destaca que as cidades atuais, pelo menos aparentemente, estão preocupadas em criar uma imagem positiva e de alta qualidade, procurando uma arquitetura e formas de projeto urbano que atendam a essa necessidade. Dar determinada imagem à cidade por meio da organização de espaços urbanos espetaculares se tornou um meio de atrair capital e pessoas num período (que começou em 1973) de competição interurbana e de empreendedorismo urbano intensificado.

Neste sentido, Sánchez (2003:67) ressalta “um amplo leque de governos locais é seduzido por esse 'modelo', fazendo uma opção clara pelo chamado 'planejamento estratégico de cidade', cujo fundamento constrói a necessidade da transformação da cidade em mercadoria".

Entretanto, a imagem da cidade depende de sua forma de crescimento, que pode ser caótico ou ordenado, e isso se reflete também no modo de vida das pessoas que precisam reconhecerse naquilo que vêem. A falta de interesse pela imagem da cidade é um elemento que corrói também o ser humano. É necessário desenvolver uma cultura urbana, o que não significa somente o embelezamento das cidades. É preciso também, segundo Pallamin et al. (2002:22), eliminar a injustiça social enfatizando a co-responsabilidade da comunidade no trato da cidade e das políticas públicas. O autor cita as formulações de Negt para discutir esse aspecto:

Uma cidade sem justiça eqüitativa pode ter a beleza que quiser, nunca será

capaz de desenvolver uma cultura verdadeiramente urbana. Pessoas que prejudicam a comunidade ou que a relegam ao abandono acabam prejudicando a si mesmas, entrando elas próprias numa espécie de processo de deterioração. Por isso atribuo à comunidade tanta importância para o desenvolvimento cultural. (NEGT apud PALLAMIN et al., 2002:25).

Essa reflexão confirma a importância do comprometimento da comunidade para a concretização de projetos urbanos e sugere uma análise do planejamento urbano, entendendo a cidade como lugar privilegiado para o desenvolvimento de uma identidade local.

No Brasil, ao longo do século XX, um grande número de cidades nasceram, cresceram e se desenvolveram. Foi nesse século que o país mais se urbanizou. A evolução do crescimento da população urbana, considerando-se esse período, é bastante ilustrativa. É a partir da década de 70 que se inverte, com força, a relação ruralurbana até então vigente.

Movimento, Porto Alegre, v. 11, n. 3, p. 49-66, setembro/dezembro de 2005 
Hoje, o território nacional abriga 170 milhões de habitantes. Chegamos ao ano de 2000 com $137.755 .550^{6}$ de brasileiros vivendo em áreas urbanas, o que significa que $81 \%$ da população brasileira moram em cidades.

Muitas foram as conseqüências desse veloz processo. O fenômeno de urbanização provocou o agravamento do histórico quadro de exclusão social tornando mais evidente a marginalização e a violência urbana que, atualmente, são motivos de grande apreensão, tanto para moradores e usuários, quanto para o governo das cidades.

Entretanto, o processo generalizado de transformação de cidades brasileiras que experimentamos no início de um novo século e que podemos chamar apropriadamente de reforma urbana, nos reporta a um dos processos constitutivos dessa reforma que concentra uma das principais características da intervenção nas cidades: o processo de mobilidade crescente de pessoas, combinado a um processo crescente de celebração de uma urbanidade idealizada, que pressupõe o entendimento do espaço simbólico das cidades.

Um intenso consumo de urbanidade parece caracterizar esses novos tempos em diversas capitais do país. O discurso ancorado na chamada "qualidade de vida" desdobra-se em atributos urbanos em que beleza, limpeza, regularidade e segurança dos espaços públicos são condições necessárias para a vida cotidiana. As dimensões do lazer e da cultura se interligam. Os museus, as livrarias, as lojas de CDs, os shoppings com cinemas e parques de diversões eletrônicos, os centros de compra, os centros de convenções, parques públicos, praças e jardins, por todo lado se multiplicam em territórios centrais das cidades.

A cidade, em alguns de seus pontos altos, deve ser cúmplice da explicitação de marcas ou símbolos do lugar ocupado ou buscado, numa ânsia de particularidade que a distinga e que congreguem habitantes e turistas, cada vez mais presentes em seu cotidiano.

Poderíamos localizar neste sentido algumas capitais do Brasil que se conectam a uma marca identitária local, trazendo alguns exemplos para reflexão: São Paulo liga-se com sínteses como "pólo econômico", Rio de Janeiro como "cidade maravilhosa", Porto Alegre como "efervescência política", Fortaleza, "sociabilidade agradável, cordial e hospitaleira". Em Curitiba, essas imagens estão

6 Dados do IBGE/2002.

Movimento, Porto Alegre, v. 11, n. 3, p. 49-66, setembro/dezembro de 2005 
representadas pelas soluções urbanísticas funcionais e com forte apelo estético, que vendem a idéia de que nessa cidade é possível ter uma "vida urbana tranqüila do ponto de vista social", além da divulgação de projetos ambientais que visam possibilitar um "viver urbano com mais qualidade de vida para os seus habitantes", gerando sínteses como: "cidade-modelo", "cidade dos parques públicos", "cidade planejada", "cidade moderna e humana", "cidade ecológica", "metrópole verde". De acordo com García (1999):

Em nível europeu, podemos tomar como exemplo alguns casos de cidades onde seus governos locais desenvolveram nos últimos anos importantes políticas de promoção das cidades, como Barcelona e Bilbao (Espanha),

Glasgow (Escócia) e Lisboa (Portugal). Nestes casos, os principais elementos construtores desta urbanidade, constituídos no nível da imagem em fatores de atratividade turística são, por um lado, os novos espaços de renovação urbana, as grandes obras urbanísticas recentes, onde a arquitetura desempenha um papel preponderante na consolidação de marcos mais emblemáticos e, por outro lado, também a diversificação da oferta nos circuitos culturais e de consumo de bens e serviços, assim como a posição geográfica estratégica (BENACH, et al. 1998, apud GARCÍA, 1999).

Nesta perspectiva, nunca se procurou tanto a diferença. Vultuosos investimentos vêm sendo aplicados na construção da imagem ${ }^{7}$ urbana, tendência esta que atinge todas as grandes metrópoles do mundo. A questão presente na contemporaneidade é a cidade entendida como objeto de desejo, a qual se vê insistentemente provocada a ter uma singularidade e a competir por uma produção mercantil que tem invadido todos os setores de produção de bens materiais.

Para Fernandes (2001:323), “a busca sôfrega do conjunto de cidades por marcas identitária apenas aparentemente as distingue". Continua afirmando que, mais corretamente, talvez pudéssemos falar de um "intencionalismo do particularismo", que as reúne em estratégias consensuais de desenvolvimento, derivadas de uma divisão do trabalho da urbanidade, na qual cada cidade deve representar um papel específico. Mais do que nunca, a arquitetura e as cidades estão à procura de uma identidade que as singularize. Por isso, a construção das cidades do futuro coloca em questão a busca pela construção de uma auto-imagem positiva, dentre as quais Curitiba claramente se situa, assim como outras capitais do país.

7 Ferrara (2000: 57) afirma que a imagem pode ser "alguma coisa que não existe, mas se simula imaginariamente existente e de forte apelo interativo (...) assim, a imagem não é outra coisa senão a leitura que dela se faz; imagens, portanto, de uma relação icônica e interpretante".

Movimento, Porto Alegre, v. 11, n. 3, p. 49-66, setembro/dezembro de 2005 


\section{Curitiba e a busca por uma marca identitária: auto-imagem positiva por intermédio de espaços de lazer que conectam natureza, cultura e esporte}

A cidade de Curitiba vem despertando a atenção da opinião pública nacional e internacional, nos últimos anos, por meio da divulgação constante da atuação de gestões públicas diferenciadas, marcadas com mais ênfase a partir de Jaime Lerner (conhecido como "urbanista-técnico competente"), seguido por Rafael Grecca e recentemente com o prefeito Cássio Taniguchi (engenheiro do IPPUC, formado pelo ITA, conhecido como "técnico-racional"). A cidade, portanto tem sido considerada uma "cidade-modelo", com sínteses como "cidade ambientalmente correta", "capital ecológica", "capital social", entre outras, em função de suas experiências urbanas, as quais são consideradas inovadoras e criativas.

Vale ressaltar, que essa imagem é alavancada por meio de inúmeros projetos lançados pelo poder local, os quais têm como pano de fundo a intenção de dar à cidade uma forma e uma identidade específica, centrada muitas vezes em espaços destinados a experiências no âmbito do lazer, cultura e esporte.

Considerando esse aspecto, percebe-se a construção e a apreciação estética da paisagem ${ }^{8}$ urbana como uma das marcas identitárias possíveis da cidade de Curitiba. Especificamente destaca-se a estratégia urbanística de agregar paisagens naturais, modelos arquitetônicos modernos e projetos culturais em diversos espaços públicos destinados ás práticas corporais e de lazer como marca da cidade. Observa-se certa coerência de linguagem arquitetônica desses ambientes criados ou preservados, constituindo-se em premissa básica para o alcance da unidade de significados necessária à imagem sintética da "cidade que deu certo".

Nesta direção, García (1996) assinala a arquitetura como um dos campos de saber especializados que contribui, junto com investimentos de outros campos do conhecimento, para a construção de uma imagem-sintética. A semelhança dos cenários dos diversos

8 Santos (1996:83) define paisagem como "conjunto de elementos naturais e artificiais que fisicamente caracterizam uma área. A rigor, a paisagem é apenas a porção de configuração territorial que é possível abarcar com a visão".

Movimento, Porto Alegre, v. 11, n. 3, p. 49-66, setembro/dezembro de 2005 
parques sugere a adoção de um modelo de parques públicos na cidade de Curitiba como referencial positivo no contexto brasileiro, colocando-a como realidade "singular em meio ao caos", como contraponto, como prova de que "pode dar certo".

García (1996:86), ao analisar esse contraponto, argumenta que o discurso dominante aciona também a imagem-síntese dos anos 90 ("Curitiba - capital ecológica") como sendo "capaz de contribuir para que seja exorcizada a imagem negativa do Brasil no exterior". A autora complementa dizendo que a imprensa internacional endossa essa perspectiva ao se referir a Curitiba como "uma rara história de sucesso ecológico em um país mais freqüentemente visto como um fracasso ambiental" (Financial Times, 30-08-91). Outra declaração que demonstra este aspecto é a de que "se houver uma cidade modelo no futuro, ela fará as coisas que Curitiba está fazendo" (Latin American Newsletter, 13-02-92).

Portanto, para a autora "claro está que se trata de uma valorização subjetiva, porém tecnicamente agregada àquilo que se deseja colocar em circulação no mercado".

Curitiba, nos últimos anos, tem sido referência para planejadores urbanos, ambientalistas e líderes municipais, os quais visitam a cidade para conhecer as soluções apontadas pelas políticas públicas locais a alguns males urbanos considerados universais (saúde, transporte, educação, lazer, políticas ambientais, etc.). Mas tais visitas visam, principalmente, conhecer os modelos de espaços públicos que associam modernidade, lazer e cultura, promovendo uma forte mediação entre a sociedade e a natureza.

Os parques, as praças e os bosques viraram "praias" dos curitibanos. São mais de 300 praças, 43 parques e diversos bosques. Neles circulam, em média, 150 mil pessoas por semana. Segundo observação de campo deste estudo, das pessoas que aliam caminhadas, corridas e exercícios com pontos de encontros, principalmente nos fins de semana, às famílias de diferentes camadas sociais ${ }^{9}$ que buscam espaços para as mais diversas vivências no âmbito do lazer.

Para exemplificar esse modelo podemos citar alguns espaços como o Parque Tanguá, que envolve uma área de 235 mil metros

9 Em pesquisa realizada pela RPC (Rede Paranaense de Comunicação), no primeiro semestre de 2003, em que foram colocados computadores disponíveis à população em todos os terminais de transporte coletivo, para que pudessem opinar sobre a qualidade dos serviços públicos, foi detectado que o serviço mais eficiente para o cidadão curitibano é a oferta dos espaços públicos de lazer e o mais deficiente é a segurança pública.

Movimento, Porto Alegre, v. 11, n. 3, p. 49-66, setembro/dezembro de 2005 
quadrados com a presença de dois lagos e um túnel artificial o qual pode ser visitado de barco ou a pé. Este Parque preserva grandes áreas verdes, e é dotado de ancoradouro, ciclovia, pista de Cooper, churrasqueiras, mirante, lojas de artigos típicos, lanchonetes e amplos estacionamentos.

Também são ícones desse modelo o Parque São Lourenço, a Ópera de Arame e a Pedreira Paulo Leminski, que mantém as mesmas características estruturais, mas chamam atenção devida á forma integrada como a natureza, a cultura, o esporte e o lazer se potencializam. Essa integração é possível por intermédio da transformação de uma antiga fábrica em Centro de Criatividade ou antigas Pedreiras em teatro e espaços para grandes eventos, administrados pela Fundação Cultural de Curitiba. Esses ambientes são destinados à realização de atividades ligadas às artes plásticas, pesquisa de som, luz e movimento, exposições, shows, práticas corporais, os quais dinamizam diferentes conteúdos culturais no tempo/espaço de lazer do cidadão curitibano.

O modelo urbanístico de espaços públicos que contemplam a relação cidade/natureza/cultura/esporte e lazer proposto para Curitiba tende, portanto, a lhe conferir uma marca identitária de auto-imagem positiva. Embora o planejamento dos espaços seja de fundamental importância para oportunizar experiências no âmbito do lazer e dos esportes, essas intervenções deverão estar sempre que possível conectadas a políticas públicas que realmente atendam aos anseios do cidadão.

\section{O repensar sobre o espaço "cidade": novo desafio para as políticas públicas de lazer e esportes}

Como pensar sobre as políticas públicas de lazer e esportes sem antes discutir sobre o que é uma cidade? Trata-se de um aglomerado de casas, prédios e empresas? Trata-se de extensas avenidas que recortam bairros e histórias e são previstas para circulação de um número cada vez maior de carros? Trata-se da combinação de poluição sonora e visual, num misto de vozes, buzinas, motores de automóveis, luminosos, propagandas? A resposta poderia ser

10 Para Milton Santos (1997), "o conceito de lugar induz a uma análise na dimensão da existência, pois se refere a um tratamento do mundo vivido". Para o autor, o lugar expressa relações de ordem objetiva em articulação com relações subjetivas, relacões verticais resultado do poder hegemônico, imbricadas com relações horizontais de coexistência e resistência. Daí a força do lugar.

Movimento, Porto Alegre, v. 11, n. 3, p. 49-66, setembro/dezembro de 2005 
sim: A cidade é tudo isso. No entanto, a cidade também significa a relação do sujeito consigo mesmo, com o outro e com o lugar ${ }^{10}$ onde vive. E os espaços produzidos resultantes dessas relações precisam ser percebidos na sua dimensão humana, ou seja, no que uma cidade e alguns de seus cenários significam para quem nela vive e para quem deles usufrui, no âmbito do lazer e do esporte.

Qualquer que seja a sua escala, a cidade é uma organização viva, dinâmica, com suas diversificadas partes em permanente interação. Motivo pelo qual o estudo sobre as cidades tem sofrido grandes transformações, especialmente nas últimas décadas, não apenas em relação às perspectivas do que é uma cidade, seu papel, sua função, mas também com o surgimento de novos conceitos da dinâmica urbana.

Neste sentido, Carlos (2003:13) apresenta os seguintes questionamentos:

O que é pensar a cidade e o urbano hoje? [...] como pensar as contradições do mundo moderno, o que aparece como novo e o que está posto como permanência; como ambos se realizam? Como pensar o que é singular e específico no Brasil e o que se constitui como conseqüência dos processos mundiais? Como desvendar os conteúdos do processo de urbanização hoje? Qual é o alcance da teoria? O que é um projeto para cidade? Qual é o seu conteúdo e o caminho para sua construção? Onde se gesta? Até que ponto o "ato de planejar a cidade" a partir do estado, de suas necessidades e urgências constrói e dá conteúdo a um projeto para a cidade?

Trata-se de questões instigantes e desafiadoras. Se a construção da problemática urbana tem como ponto de partida a cidade, discute Carlos (2003), ela deve dar conta do fato de que a realidade urbana se generaliza no espaço. Por outro lado, a cidade articula teoria e prática, além de se revelar no plano do vivido e do subjetivo, o qual introduz referenciais, identidades e lutas, revelando a produção social do espaço urbano.

Ao iniciar as primeiras incursões sobre o modelo da gestão pública referente ao lazer e ao esporte adotado em Curitiba, depareime com uma questão bastante importante: o modelo de planejamento e gestão dos espaços destinados ao lazer, esporte, e cultura e as diversas possibilidades de intervenção nesses ambientes não é algo que possa ser tomado independentemente de um contexto maior de discussão sobre o planejamento, a gestão e a dinâmica urbana de uma cidade. Portanto, um enfoque é fundamental para essa análise: trata-se de visualizar a forma pela qual a evolução do tratamento da questão urbana vem se desenvolvendo, buscando inserir a discussão sobre o modelo das políticas públicas de lazer e esportes nesse contexto, no que se refere tanto ao planejamento dos espaços, quanto aos programas de intervenção.

Movimento, Porto Alegre, v. 11, n. 3, p. 49-66, setembro/dezembro de 2005 
Faz-se necessário, para tanto, reconhecer o tempo/espaço do lazer como uma prática social, que envolve a dimensão humana e de especial importância à comunidade. Destaca-se também a pertinência de se contemplar na elaboração de políticas públicas de lazer e esportes a formação permanente dos agentes sociais envolvidos tanto com as intervenções práticas, como com o planejamento de espaços e equipamentos para tais vivências.

Outro ponto a ser considerado pelos gestores públicos, se realmente o intuito for construir políticas públicas que priorizem preocupações com a perspectiva inclusiva da prática do lazer e esporte, assim como, o reconhecimento da multidisciplinariedade do setor, é a valorização da produção científica na área de Educação Física, a qual nas últimas décadas tem possibilitado um diálogo ampliado entre diferentes áreas do conhecimento, com especial ênfase no campo das ciências sociais e humanas.

Planning urban space in modern society: public management in search of urban trademarks in the city of Curitiba

Abstract: Due to the spatial and social transformation occurred in the last decades in major cities, it is a good time now to start to discuss urban planning "in a sense of form" of some city spaces. In other words, what is the mea-ning of the public spaces to the general population of that particularly city? This is the starting point for this article, since the creation process of urban space in the city Curi-tiba is noticeable, initially like morphological changes that is based on some paradigms in the cities' modernization process, among them the search for some urban trademarks. In this brief analysis I like to point out some characteristics of urban planning of the public spaces in the city of Curitiba, with special emphasis to modern tendencies.

Keywords: city, urban planning, public polices, space.

Espacio y planeamiento urbano en la sociedad contemporánea: políticas públicas y la búsqueda por una marca identitária de la ciudad de Curitiba

Resumen: Delante de las transformaciones espaciales y sociales ocurridas en las últimas décadas en las grandes metrópolis, son oportunas las discusiones relativas al planeamiento urbano cuando nuestra intención es analizar el "sentido de la forma" de algunos espacios de la ciudades. Ese es el punto de partida para este artigo, pues el proceso de formación del espacio urbano de Curitiba es percibido, inicialmente, como un cambio morfológico, que tiene como escenario algunos de los paradigmas del proceso de modernización de las ciudades, entre ellos, la búsqueda por señales de identidad. Pretendo, en este breve análi-

Movimento, Porto Alegre, v. 11, n. 3, p. 49-66, setembro/dezembro de 2005 
sis, apuntar algunas características de las formas de producción de espacios por las cuales la práctica urbanística y arquitectónica tiene pasado, dando énfasis especial a las tendencias contemporáneas.

Palabras-clave: ciudad, planeamiento urbano, políticas públicas, espacio.

\section{Referências}

ARANTES, A. A. O espaço da diferença. Campinas: São Paulo: Papirus, 1999.

CARLOS. A. F. A.; LEMOS. A. I. G. (Orgs). Dilemas urbanos: novas abordagens sobre a cidade. São Paulo: Contexto, 2003.

CURITIBA, PREFEITURA MUNICIPAL DE CURITIBA. Curitiba, na prática. Curitiba: IPPUC, 2002.

FERREIRA, A B. H. Novo dicionário da língua portuguesa. 2 .ed. Rio de Janeiro: Nova Fronteira, 1986.

GARCIA. F.E.S. Cidade espetáculo: política, planejamento e city marketing. Curitiba: Palavra, 1997.

Curitiba, imagem e mito: reflexões acerca da construção social de uma imagem hegemônica. Dissertação de mestrado. Rio de Janeiro: Instituto de Pesquisa e Planejamento Urbano e Regional, IPPUR - UFRJ, 1993.

O city marketing de Curitiba: cultura e comunicação na construção da imagem urbana. In DEL RIO, Vicente; OLIVEIRA, Lívia (orgs). Percepção Ambiental: a experiência brasileira. São Paulo. Studio Nobel, 1996.

GARCÍA. F.E.S; RIBEIRO. A. C. T. A nova face da gestão da cidade no final do século. In ALMEIDA, Elisa Reis Maria Hermínia Tavares de; FRY, Peter (orgs). Política e cultura: visóes do passado e perspectivas futuras. São Paulo. Hucitec, 1996.

GIDDENS, A. As conseqüências da modernidade. São Paulo: Ed. da UNESP, 1991.

_... Modernidade e identidade. Rio de Janeiro: Zahar Ed., 2002.

HARVEY, D. Condição pós-moderna: uma pesquisa sobre as origens da mudança cultural. São Paulo: Loyola, 2000.

Do gerenciamento ao empresariamento urbano. In: Revista espaço \& debates. São Paulo, ano XVI, n³9: 48-64, 1996.

JACOBS, J. Morte e vida de grandes cidades. São Paulo: Martins Fontes, 2000. (Coleção a)

LEFEBVRE, H. A vida cotidiana no mundo moderno. São Paulo: Ática, 1991.

Movimento, Porto Alegre, v. 11, n. 3, p. 49-66, setembro/dezembro de 2005 
_.. A revolução urbana. Belo Horizonte; Ed. UFMG, 1999.

_. O direito à cidade. São Paulo: Documenta, 1969.

MATIELLO, A .M. A sustentabilidade no planejamento e gestão de parques urbanos em Curitiba - PR: uma questão paradigmática? Dissertação de mestrado. UFSC. Florianópolis, 2001.

MENEZES, C. L. Desenvolvimento urbano e meio ambiente: a experiência de Curitiba. Campinas, SP: Papirus, 1996

NEGT. O . Espaço Público e experiência. In Pallamin, V.M.; Ludemann, M. (coord) Cidade e cultura. São Paulo: Estação Liberdade, 2002.

PALLLAMIN, V. M.(org); LUDEMANN, M. (Coord). Cidade e cultura: esfera pública e transformação urbana. São Paulo: Estação Liberdade, 2002.

RECHIA, S. Parques Públicos da cidade de Curitiba: A relação Cidade-Natureza nas Experiências de Lazer. Tese de Doutorado. Unicamp. Campinas, 2003.

SÁNCHEZ, F. A reinvenção das cidades para um mercado mundial. Chapecó Argos, 2003.

SANTOS, M. A natureza do espaço: técnica e tempo, razão e emoção. São Paulo: HUCITEC, 1996.

SANTOS, M. Metamorfose do espaço habitado: fundamentos teóricos e metodológicos da geografia. 5a. Ed. São Paulo: HUCITEC, 1997 a.

Técnica, espaço, tempo: globalização e meio técnico-científico informacional. $3^{\mathrm{a}}$. Ed. São Paulo: HUCITEC, 1997b.

Território e Sociedade. Entrevista com Milton Santos. $2^{a}$. Ed. São Paulo: Editora Fundação Perseu Abramo, 2000. 2002 .

SZMRECSANYI, M.I. Lazer e consumo: espacos públicos e semipúblicos no cotidiano urbano. In: BRUNHS, H.T.; GUTIERREZ, G. (Orgs). Representações do lúdico: /I ciclo de debates lazer e motricidade. Campinas: Autores Associados, 2001.

YÁZIGI, E. A alma do lugar: turismo, planejamento e cotidiano. São Paulo: Contexto, 2001.

Recebido em: 31.08 .05

Aprovado em: 21.11.05

* Doutora em Educação Física. Membro pesquisador do CEPELS/UFPR. Professora do programa de pós-graduação e do curso de graduação em Educação Física da UFPR.

Movimento, Porto Alegre, v. 11, n. 3, p. 49-66, setembro/dezembro de 2005 